\title{
Ice-edge detection from Japanese C-band radar and high-frequency radar coastal stations
}

\author{
K. SHIRASAWA, ${ }^{1}$ N. EBUCHI, ${ }^{1}$ M. LEPPÄRANTA, ${ }^{2}$ T. TAKATSUKA ${ }^{1}$ \\ 'Institute of Low Temperature Science, Hokkaido University, Sapporo, Hokkaido, Japan \\ ${ }^{2}$ Department of Physics, University of Helsinki, Helsinki, Finland \\ E-mail: matti.lepparanta@helsinki.fi
}

\begin{abstract}
A C-band sea-ice radar (SIR) network system was operated to monitor the sea-ice conditions off the Okhotsk Sea coast of northern Hokkaido, Japan, from 1969 to 2004. The system was based on three radar stations, which were capable of continuously monitoring the sea surface as far as $60 \mathrm{~km}$ offshore along a $250 \mathrm{~km}$ long coastal section. In 2004 the SIR system was closed down and a sea surface monitoring programme was commenced using high-frequency (HF) radar; this system provides information on surface currents in open-water conditions, while areas with 'no signal' can be identified as sea ice. The present study compares HF radar data with SIR data to evaluate their feasibility for seaice remote sensing. The period of overlapping data was 1.5 months. The results show that HF radar information can be utilized for ice-edge mapping although it cannot fully compensate for the loss of the SIR system. In particular, HF radar does not provide ice concentration, ice roughness and geometrical structures or ice kinematics. The probability of ice-edge detection by $\mathrm{HF}$ radar was 0.9 and the correlation of the ice-edge distance between the radars was 0.7 .
\end{abstract}

\section{INTRODUCTION}

Sea-ice fields are dynamic elements on the surface of freezing seas. In particular, the free boundary of a sea-ice field - the ice edge - shows dynamically and thermally forced large variability. Owing to ice drift, the ice edge may be displaced by as much as $10 \mathrm{~km} \mathrm{~d}^{-1}$ (e.g. Leppäranta, 2011). On a calm sea surface the freezing front may progress at a similar rate, as often observed in the Baltic Sea. The location of the ice edge in a given sea area is of interest, both for scientific applications, such as weather and ice forecasting, and due to practical needs, such as navigation and fishery interests.

The Institute of Low Temperature Science, Hokkaido University, Japan, has operated radar systems on the northern coast of Hokkaido to monitor the coastal sea zone. In 1969 an operative C-band sea-ice radar (SIR) network was established for continuous monitoring of the sea-ice conditions (Tabata, 1972, 1975). An extensive validation programme was performed at the time of the system start-up, and later an automatic binary classification system (ice/no ice) was developed. The annual sea-ice coverage as observed by the SIR network showed a negative trend through the observation period (1969-2004) as similarly indicated by visual observations (Shirasawa, 1998). The trend of the seasonal ice concentration integral obtained from the SIR data has been $\sim 12$ days $\left(10 \mathrm{a}^{-1}\right.$ (Ishikawa and others, 2005).

The SIR system provides information on ice concentration, ice kinematics and ice-edge dynamics, which is required by the local communities along the northern coast of Hokkaido. Economic and everyday life is dependent on sea-ice conditions. Fishery and marine transport are closed during the ice season. Since the 1990s, sea ice has been a major tourist attraction, with sea-ice observation towers and icebreaker sightseeing cruises in Mombetsu and Abashiri (http://www.bfh.jp/en/theme/theme_searchdetail/ $80020614901 /)$. Thus real-time knowledge of the location of the ice edge is critically important.

In 2004 the SIR network was closed down because of difficulties in maintaining the old-fashioned radar system after 35 years of operation. In the same year, a sea surface monitoring programme was commenced using coastal highfrequency (HF) radar, which provides information on surface currents in open-water conditions (Ebuchi and others, 2006). An interesting question was then raised as to whether the HF radar could provide any information on the ice situation, compensating to some degree for the closure of the SIR system. The present work approaches this question using the data from winter 2004. This is the only ice season for which data are available from both radars. HF radar senses the ice in a negative way, i.e. no signal is obtained from ice areas, but this is enough for the construction of the ice edge. The results given below show that HF radar information can be utilized for ice-edge mapping, although it cannot compensate fully for the SIR system.

\section{MATERIAL AND METHODS}

\section{Ice in the Sea of Okhotsk}

Freezing in the Sea of Okhotsk normally begins in late November in the north. The maximum ice extent occurs in mid-March (Fig. 1). The ice then retreats, disappearing by the beginning of June. The mean maximum annual thickness of landfast ice varies regionally between 30 and $150 \mathrm{~cm}$. On the northern coast of Hokkaido the ice season is only 3-4 months, from January to April. Hokkaido ice comes mostly from the Sakhalin region to the north, transported by ocean currents, but there is also some local ice production. Offshore of Hokkaido, the Soya Warm Current comes from the Sea of Japan and flows east along the northern coast, and tidal currents are strong. The ice conditions near Hokkaido are therefore highly variable. At times drift ice comes close to shore, at other times it drifts out of visual range from the shore. The ice edge is dynamic due to winds, strong current systems and tides (Tabata and others, 1980).

Ice conditions offshore of Hokkaido have been monitored for more than 100 years. Observations of the dates of freezing and ice break-up were started in 1892 by the 


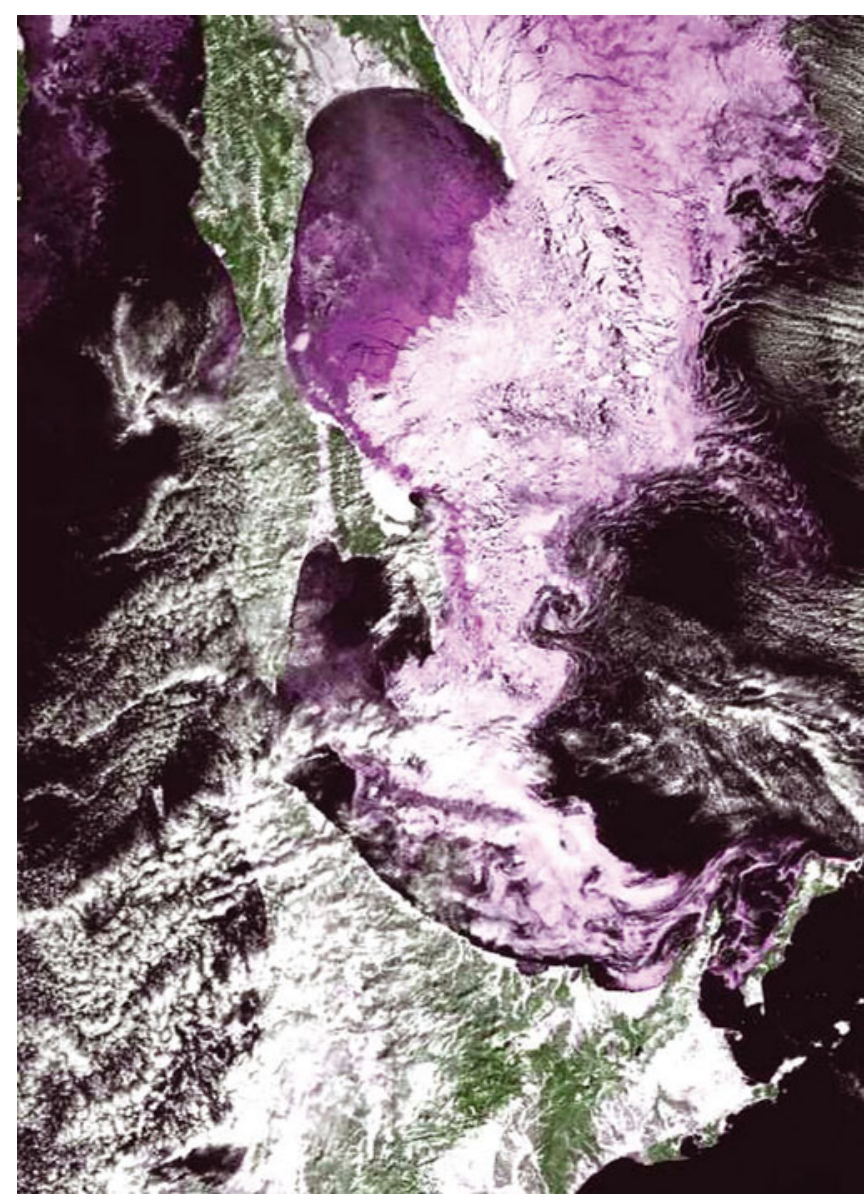

Fig. 1. Ice conditions in the Sea of Okhotsk on 10 February 2004 seen on a Moderate Resolution Imaging Spectroradiometer (MODIS) image of NASA's Terra satellite.

Abashiri Observatory. Daily visual observations of ice concentration within $\sim 20 \mathrm{~km}$ of the coastline have been carried out since 1930 (Aota and others, 1993). The SIR system was operational during 1969-2004, monitoring the ice along the entire northern coast of Hokkaido (Tabata, 1972; Shirasawa, 1998). In August 2003, an HF radar system was opened for mapping the coastal currents offshore of the Hokkaido northern coast. It was not designed for ice observations; however, it can be used to obtain indirect ice information. For comparative investigations, there is one overlapping winter in the data available from the two radar systems.

Table 1. Specification of the SIRs in Esashi and Mombetsu

Radar type

Antenna type

Beamwidth

Frequency

Transmission power

Pulse width

Repeating frequency

Resolution

Observation range

Altitude
Remotely controlled marine radar

Parabolic, $4.0 \mathrm{~m}$

Horizontal $1^{\circ}$, vertical 3

$5540 \mathrm{MHz}$

$40 \mathrm{~kW}$

$1.0 \mu \mathrm{s}$

$1 \mathrm{kHz}$

Range $150 \mathrm{~m}$, azimuth $1^{\circ}$

$50-60 \mathrm{~km}$

$440 \mathrm{~m}$ (Esashi), $300 \mathrm{~m}$ (Mombetsu)

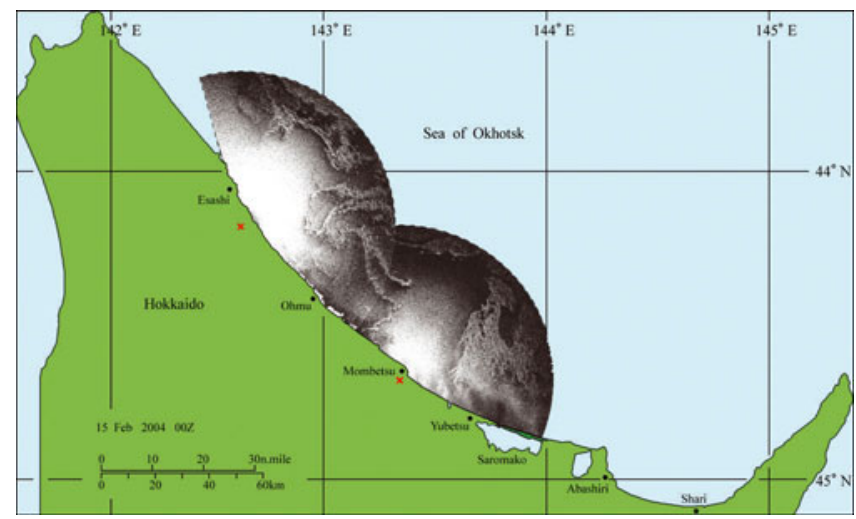

Fig. 2. Sea-ice distribution off the Okhotsk Sea coast of Hokkaido at 09:00 JST on 15 February 2004, as seen by the Esashi and Mombetsu SIR. The red crosses show the locations of the radar antennas. Also shown are the locations of the Abashiri radar station (inactive in 2004) and the HF radar stations (Ohmu and Mombetsu).

\section{SIR system}

Marine radars have been routine tools in sea-ice mapping since the late 1960s (e.g. Haykin and others, 1994). Ship radars and fixed coastal radars have been used in sea-ice navigation and in remote sensing (Tabata, 1972, 1975; Leppäranta and Palosuo, 1983; Karvonen and others, 2010). The feasibility of marine radars is based on the typically strong backscatter contrast between sea ice and open-water surfaces and consequently the ice extent and concentration can be fairly well observed. Also, there are recurring features (e.g. ice ridges) which show up repeatedly in radar imagery and allow monitoring of ice kinematics. The advantage of marine radars over satellite radars (e.g. Haykin and others, 1994; Leppäranta and others, 1998) is that their temporal resolution can be made arbitrarily small, although spatial coverage is limited.

The Hokkaido SIR network was based on three radar stations located on hilltops at altitudes of 200-440 m overlooking the coast in Esashi $\left(44^{\circ} 49^{\prime} \mathrm{N}, 142^{\circ} 37^{\prime} \mathrm{E}\right)$, Mombetsu $\left(44^{\circ} 21^{\prime} \mathrm{N}, 143^{\circ} 19^{\prime} \mathrm{E}\right)$ and Abashiri $\left(44^{\circ} 06^{\prime} \mathrm{N}\right.$, $\left.144^{\circ} 15^{\prime} \mathrm{E}\right)$. The system was capable of mapping the sea surface up to $60 \mathrm{~km}$ offshore along a $250 \mathrm{~km}$ section of coastline off the northern coast of Hokkaido. The SIR characteristics are summarized in Table 1 . The radars operated at C-band (wavelength $5.4 \mathrm{~cm}$ ) with a maximum power output of $40 \mathrm{~kW}$, a beamwidth of $1^{\circ}$ horizontal and $3^{\circ}$ vertical and a pulse width of $1 \mu$ s. They were controlled remotely from the Sea Ice Research Laboratory of Hokkaido University, Mombetsu, where the data from the radar stations were assembled via telemetry. From winter 2004 the Abashiri SIR system was no longer active.

Time series of the daily ice distribution observed by the SIR network at 09:00 JST (Japan Standard Time = GMT +9 hours) along with total ice concentration (defined as the ratio of ice area to the coverage of the composite radar imagery) during the whole sea-ice season have been archived since 1969. In addition, SIR images were taken at 3 hour intervals throughout the whole sea-ice season for further studies of coastal sea-ice dynamics and movements. Figure 2 shows the locations of the SIR stations together with an example of the sea-ice distribution off the coast of Hokkaido in the study winter. The radar data are from Esashi and Mombetsu stations. Sea-ice patches can be identified 
Table 2. Specification of the HF radar system of the Mombetsu and Ohmu stations

Radar type

FMICW (frequency-modulated interrupted continuous-wave)

Centre frequency

Sweep bandwidth Frequency sweep interval

Transmission power

Range resolution

Observation range

Azimuth resolution

Current velocity resolution

Antenna type

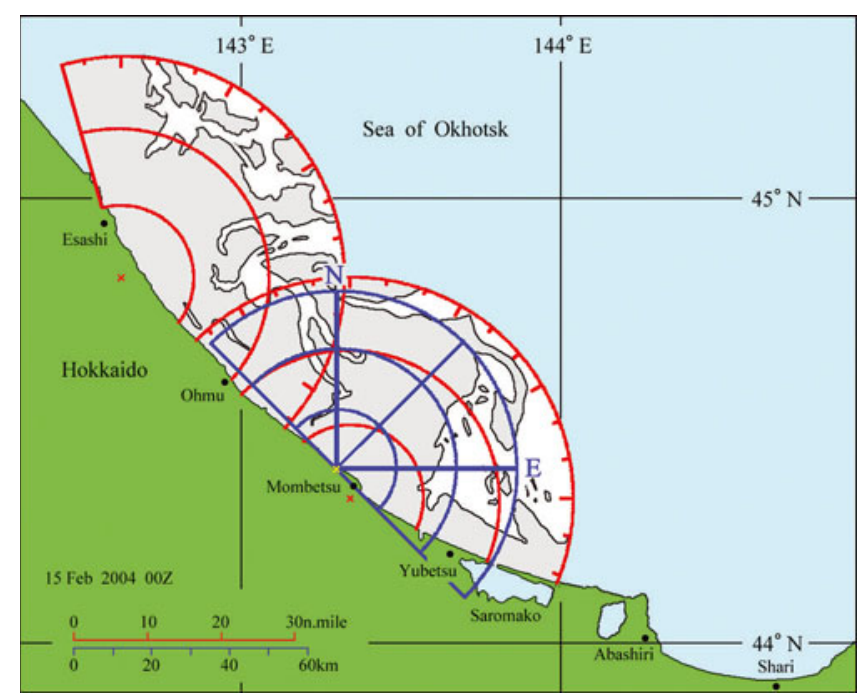

Fig. 3. Sea-ice distribution off the Okhotsk Sea coast of Hokkaido at 09:00 JST on 15 February 2004: interpretation for ice (white) and open water (grey) from Mombetsu and Esashi SIR images. Also shown is the coverage of the Esashi and Mombetsu SIRs (red circles) and the Mombetsu HF radar (blue circles) with study lines for the radar data comparison (blue lines). Ohmu HF radar circles and lines will be similar to those for the Mombetsu radar.

binary open-water/ice map can be constructed within the range of the radar, but in the case of marine radar the strength of the scattered signal bears additional information about the character of the ice.

\section{Data analysis}

The basic assumption is that SIR provides the correct iceedge information. This is motivated by more than 30 years of experience in the region, with an advanced ice-detection algorithm developed over several years (e.g. Aota and others, 1985). HF radar is a new instrument for this problem, and its ice-edge location is validated against the ice edge detected by SIR.

To evaluate the feasibility of HF radar for ice mapping, two factors are of interest. First, we must determine whether HF radar recognizes the ice edge. The first type of error appears if HF radar receives no signal although there is no ice, and the second type of error appears if HF radar receives a signal although there is ice. We need to examine these conditional error probabilities. Which type of error is more critical depends on the application of the ice-edge information. For fishing and shipping, the first error is critical when ice needs to be avoided, but for tourism associated with observation of sea ice the second error is critical.

Second, if HF radar is able to detect the ice edge, the question is how well the distance to the ice edge can be determined. HF radar provides the return signal from pixels along radial lines, and, taking the 'no return' pixels as ice, it is possible to construct the function

$$
\widehat{\ell}=\widehat{\ell}\left(\theta_{m}, t_{n}\right)
$$

where $\widehat{\ell}$ is the distance to the nearest ice edge estimated by HF radar, $\theta_{m}$ is the line direction and $t_{n}$ is the observation time. The nearest ice edge has the greatest practical interest here. From the continuous SIR imagery it is possible to sample line information for the assumed actual distances to the ice edge (Fig. 3), $\ell=\ell\left(\theta_{m}, t_{n}\right)$. The error of the HF radar 


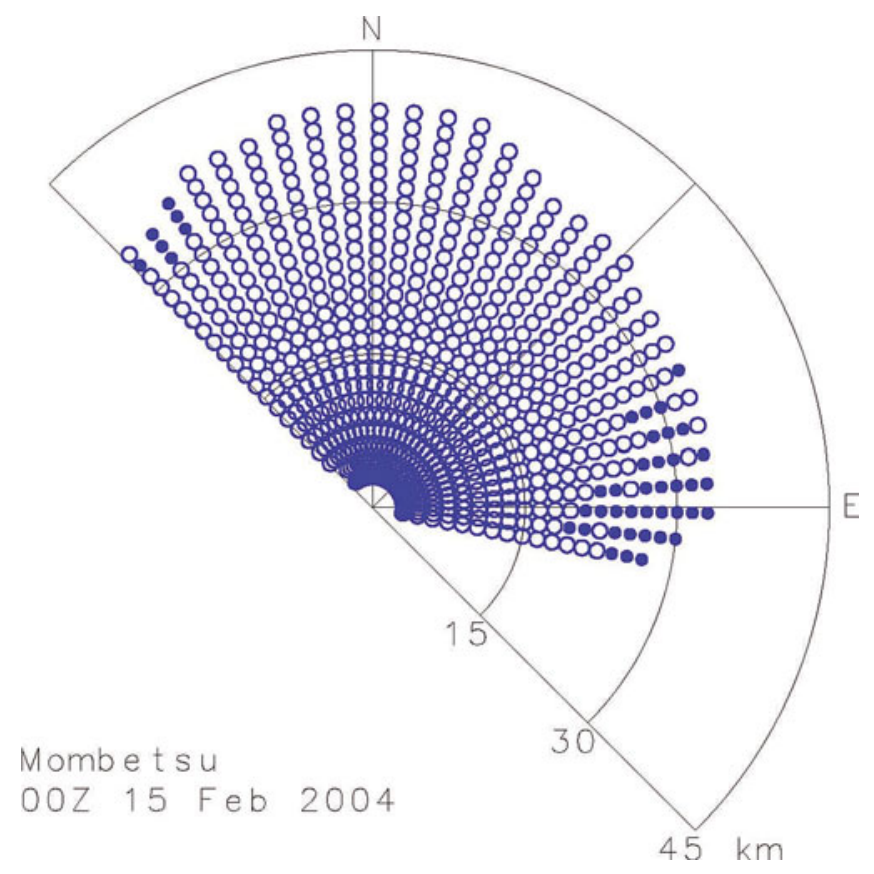

Fig. 4. Mombetsu HF radar signals on 15 February 2004: interpretation for ice (filled circles) and open water (open circles). Radar pixels with no signal return are those interpreted as ice pixels.

ice-edge estimator is thus

$$
d\left(\theta_{m}, t_{n}\right)=\widehat{\ell}\left(\theta_{m}, t_{n}\right)-\ell\left(\theta_{m}, t_{n}\right)
$$

The number of observation days was 51 (from 21 January to 11 March 2004), and, for each day, three HF radar lines were taken from Mombetsu and Ohmu data and compared with the radar imagery. The total number of lines was thus $51 \times 2 \times 3=306$. Denser spatial or temporal sampling would not provide much more additional independent statistical information.

\section{RESULTS}

\section{Ice conditions in winter 2004}

The ice season of 2004 was mild in the Sea of Okhotsk. Ice conditions in the southern part are shown in Figure 1 on a Moderate Resolution Imaging Spectroradiometer (MODIS) image. Ice floes are drifting south from Sakhalin, and the northern coast of Hokkaido is largely open, as also shown by the SIR picture 4 days later (Fig. 2). In the SIR coverage of the Esashi and Mombetsu stations this was one of the mildest sea-ice seasons since 1969 (Ishikawa and others, 2005). Drift ice appeared off the northern coast of Hokkaido within the coverage of the Esashi SIR for the first time in this winter on 17 January 2004. Sea-ice cover further expanded towards the southeast along the coast of Hokkaido. Ice concentration reached as much as $90-100 \%$ by mid-February, remained high until the end of February and then decreased, with ice disappearing completely from the radar coverage by 13 March 2004.

Figure 3 shows a binary ice/open-water map produced from the SIR data for 15 February 2004. The original SIR image is shown in Figure 2. This image provides a detailed geometrical picture of the distribution of ice in a sector up to $60 \mathrm{~km}$ from the station. This figure also shows the coverage of the three SIRs and the three comparison lines for the
Mombetsu SIR and HF radar: north $(\mathrm{N})$, northeast and east (E). Similar comparison lines were also taken for the Ohmu HF radar (not shown) overlapping both the Mombetsu and Esashi SIRs. Figure 4 shows the output from the Mombetsu $\mathrm{HF}$ radar from the same day. It is seen that the HF radar picks up the ice patches shown in the SIR picture quite well. Comparison with Figure 4 shows how the ice cover masks out HF radar signals.

\section{Statistics}

An example of SIR-HF radar data pairs for Mombetsu station is shown in Figures 3 and 4. In this case most of the ice is towards the east and is shown similarly by both radars. Since both systems measure along lines from the radar antenna, there is no reason to obtain directionally dependent results. Therefore the whole dataset can be put together, all distance pairs as independent cases, for the statistical analyses.

The number of lines with data from both radars was 306 . SIR showed ice-edge presence in 209 cases, while there were 240 identifications with the HF radar. If the HF radar gives an ice edge, the probability that it is true is 191/ $240=0.88$; if it gives no ice edge, the probability that it is true is $48 / 66=0.73$. The number of true cases follows the binomial distribution and the accuracy of the probability estimates is 0.025 . The conditional probabilities can be shown in the matrix:

$\begin{array}{llll} & & \text { Sea-ice } & \text { Radar } \\ \text { Edge } & \text { No edge } \\ \text { HF } & \text { Edge } & 0.88 & 0.12 \\ \text { Radar } & \text { No edge } & 0.27 & 0.73\end{array}$

Thus, whether there is an ice edge or not can be identified with good confidence by the HF radar. As is seen, the probabilities are not symmetric. Ice-edge detection by HF radar is reliable, while suggesting the absence of ice edge is less certain.

The location of the ice edge as the distance from the radar antenna was then examined for both radars (Table 3 ). The mean distances to different directions were within 12-18 km in the SIR data, and the overall mean error of the HF radar was $d=-0.3 \mathrm{~km}$. The standard deviations were $10-14 \mathrm{~km}$ and their differences between the radars were from $-1.2 \mathrm{~km}$ to $1.9 \mathrm{~km}$. The distance error of the HF radar is not significantly different from zero. The correlation coefficients of the radar readings were $0.63-0.78$ except in the Mombetsu east direction (0.45).

Thus we can conclude that HF radar detects ice edge with a probability of 0.9 . When there is ice, the obtained distance to the ice edge is an unbiased estimator of the target, $\widehat{\ell}=\ell$, with a correlation coefficient of 0.7 .

\section{Time series}

Time series of ice-edge detection give a clear illustration by which to compare the two radars. Figure 5 shows the cases with the highest and lowest correlations, respectively, i.e. the lines Mombetsu north and Mombetsu east. For Mombetsu north the agreement between the two radars is good. For the first 11 days there were large differences, but thereafter the dynamics of the ice edge was picked up similarly by both radars; only on days 19 and 49-50 were there larger differences. It is shown below that the large differences are due to low ice concentration, where it is uncertain whether HF radar will receive a signal or not. Also in the lower-correlation case, Mombetsu east, the 

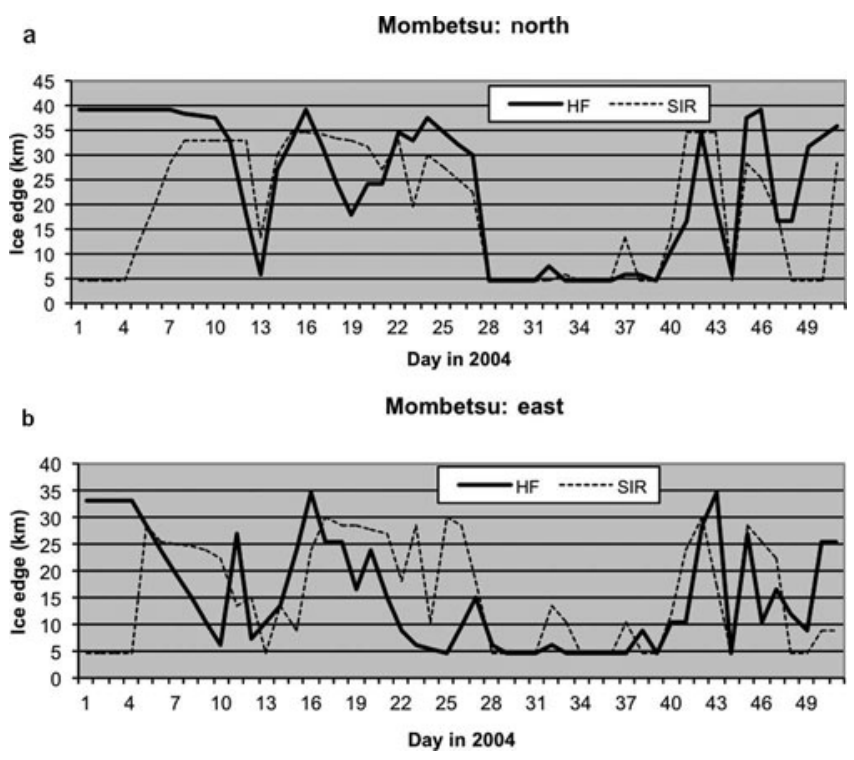

Fig. 5. Time series of distance from the radar antenna to the ice edge for the lines (a) Mombetsu north and (b) Mombetsu east as detected by HF radar and SIR. The missing values have been interpolated. Day 1 is 21 January 2004.

radars gave comparable signals. There were large differences in the beginning and at the end of the ice season, but otherwise only on days 22-26 was a large difference observed. The time-series result thus supports the results based on the overall statistics in the previous subsection and shows that the two radars detect the ice edge in a similar way. Occasional deviations from the good correlation are examined further below.

It seems plausible that the difference in the radar detection, or the error of the HF radar as we consider SIR to be correct, depends on the sea-ice concentration. HF radar may receive signal from a low-concentration ice field and interpret it as open water. Figure 6 shows the time series of ice concentration and ice-edge detection error together. As expected, when the ice concentration is low the error is large. When the ice concentration is large, the HF radar can map leads or coastal polynyas and their sizes well, while in low ice concentration the situation is difficult. In applying HF radar for sea-ice charting, indirect general knowledge of prevailing ice concentration therefore significantly increases the probability and accuracy of ice-edge detection. Such general knowledge can be obtained from operational satellite data or from the historical record.

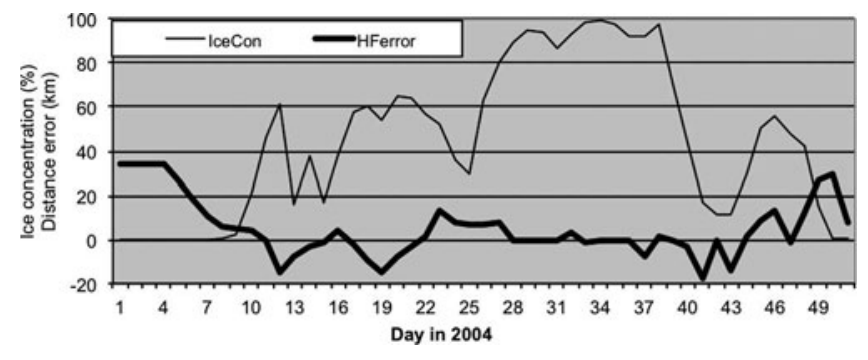

Fig. 6. Ice concentration (\%) and the error of the distance to the ice edge $(\mathrm{km})$ determined by HF radar in Mombetsu in 2004. Day 1 is 21 January 2004.

\section{CONCLUSIONS}

In 1969 an operative C-band SIR network was established for continuous monitoring of sea-ice conditions off the northern coast of Hokkaido (Tabata, 1972, 1975). The system was based on three radar stations, which were capable of continuously monitoring the sea surface as far as $60 \mathrm{~km}$ offshore along a $250 \mathrm{~km}$ long coastal section. In August 2004 the radar system was closed down, while in July 2003 a sea surface monitoring programme was commenced using coastal HF radar, which provides information on surface currents in open-water conditions (Ebuchi and others, 2006).

A question was raised as to whether HF radar can provide information about the ice situation and therefore compensate to some degree for the loss of the SIR system. It is assumed that SIR gives the correct ice situation based on its use for over 35 years. The present work has approached this question with the data from winter 2004, the only season for which there are data available from both radars. The HF radar senses the ice in a negative way: no signal is obtained. But this is enough for the construction of the ice edge to evaluate how well the HF radar provides the ice edge and how the HF data should be used for ice-edge tracking. The results show that HF radar information can be utilized for ice-edge mapping, although it cannot compensate fully for the loss of the SIR system. The probability of detecting the ice edge by HF radar is 0.9 and the distance estimate is unbiased, with a correlation coefficient of 0.7. Larger uncertainties appear in low ice concentration. Combined with drifters on ice, HF radar will be a highly interesting tool to map ice drift and surface currents together.

The location of drift ice is of great interest to people living in coastal areas, in particular because of fishery interests. Also, in Mombetsu and Abashiri, where tourists are taken

Table 3. The statistics of the distance $(\mathrm{km})$ of the ice edge from the HF radar and SIR stations in Mombetsu and Ohmu. The line directions $\mathrm{N}$, $\mathrm{NE}$ and $\mathrm{E}$ are shown separately

\begin{tabular}{|c|c|c|c|c|c|c|}
\hline & \multicolumn{3}{|c|}{ Mombetsu } & \multicolumn{3}{|c|}{ Ohmu } \\
\hline & $\mathrm{N}$ & $\mathrm{NE}$ & $\mathrm{E}$ & $\mathrm{N}$ & $\mathrm{NE}$ & $\mathrm{E}$ \\
\hline Mean (HF radar) & 20.4 & 14.2 & 13.4 & 14.5 & 15.6 & 14.8 \\
\hline Std dev. (HF radar) & 13.5 & 13.5 & 9.8 & 13.5 & 10.1 & 13.2 \\
\hline Mean (SIR) & 18.5 & 12.3 & 15.4 & 14.9 & 17.7 & 16.0 \\
\hline Std dev. (SIR) & 12.8 & 11.6 & 10.8 & 12.5 & 11.3 & 13.9 \\
\hline Mean difference & 1.9 & 1.9 & -2.0 & -0.4 & -1.9 & -1.2 \\
\hline Correlation & 0.78 & 0.66 & 0.45 & 0.67 & 0.63 & 0.73 \\
\hline
\end{tabular}


into drift ice fields by small icebreakers, it is important to know how far the ice edge is from the coast and where it is accessible by the cruises. Near-real-time information with high temporal resolution provided by a land-based radar system is most important for local-scale practical applications. Satellites have low time resolution, and also optical and infrared windows are weather-dependent.

\section{ACKNOWLEDGEMENTS}

This work is part of the Japanese-Finnish Cooperative Program 'Ice climatology in the Okhotsk and Baltic Seas', supported by a grant-in-aid from the Japanese Ministry of Education, Culture, Sport, Science and Technology, the Japan Society for the Promotion of Science, and the Academy of Finland. Additional support was provided to Matti Leppäranta by the project 'Mesoscale dynamicthermodynamic modelling of sea-ice' (\#122412) funded by the Academy of Finland.

\section{REFERENCES}

Aota M, Oi M, Ishikawa M and Fukushi H (1985) Detection of an ice-forming area by radar and satellite. Ann. Glaciol., 6, 252-253

Aota M, Ishikawa M, Murai K and Hirata T (1993) Variation of accumulated ice concentration off Abashiri, Okhotsk Sea coast of Hokkaido. Oceanogr. Jpn, 2(4), 251-260 [in Japanese]

Barrick DE, Evans MW and Weber BL (1977) Ocean surface currents mapped by radar. Science, 198(4313), 138-144 (doi: 10.1126/science.198.4313.138)

Ebuchi $\mathrm{N}$ and 7 others (2006) Observation of the Soya Warm Current using HF ocean radar. J. Oceanogr., 62(1), 47-61 (doi: 10.1007/s10872-006-0031-0)

Gurgel K-W, Essen H-H and Kingsley SP (1999) HF radars: physical limitations and recent developments. Coastal Eng., 37(3-4), $201-218$

Haykin S, Lewis EO, Raney RK and Rossiter JR (1994) Remote sensing of sea ice and icebergs. Wiley, New York
Ishikawa M, Takatsuka T and Shirasawa K (2005) Distributions of pack ice in the Okhotsk Sea off Hokkaido observed using a seaice radar network, January-March 2004. Contrib. Inst. Low Temp. Sci., Ser. A 63, 11-33

Karvonen J, Heiler I and Haapala J (2010) Ice drift information retrieval from radar time series. In Proceedings of the 20th IAHR International Symposium on Ice, 14-18 June, 2010, Lahti, Finland. International Association for Hydro-Environment Engineering and Research, Madrid. CD-ROM http://www.riverice. ualberta.ca/IAHR\%20Proc/20th\%20lce\%20Symp \%20 Lahti\%202010/Papers/013_Karvonen.pdf

Leppäranta M (2011) The drift of sea ice, 2nd edn. Springer, Heidelberg

Leppäranta M and Palosuo E (1983) Use of ship's radar to observe two-dimensional ridging characteristics. In Proceedings of the 7th International Conference on Port and Ocean Engineering under Arctic Conditions (POAC '83), 5-9 April 1983, Helsinki, Finland. Technical Research Center of Finland (VTT), Espoo, 138-147

Leppäranta M, Sun Y and Haapala J (1998) Comparisons of sea-ice velocity fields from ERS-1 SAR and a dynamic model. J. Glaciol., 44(147), 248-262

Shirasawa K (1998) Sea-ice in the Okhotsk Sea - effects by global warming? In Japan Society of Hydrology \& Water Resources Editorial Board ed. Hydrology and water resources in snowcovered regions. Shinzansha Scitech, Tokyo, 191-204 [in Japanese

Squire VA, Dugan JP, Wadhams P, Rottier PJ and Liu AK (1995) Of ocean waves and sea ice. Annu. Rev. Fluid Mech., 27, 115-168 (doi: 10.1146/annurev.fl.27.010195.000555)

Tabata T (1972) Radar network for drift ice observations in Hokkaido. In Karlsson T ed. Sea Ice, Proceedings of an International Conference, 10-13 May 1971, Reykjavík, Iceland. National Research Council, Reykjavík, 67-71

Tabata T (1975) Sea-ice reconnaissance by radar. J. Glaciol., 15(73), 215-224

Tabata T, Kawamura T and Aota M (1980) Divergence and rotation of an ice field off Okhotsk Sea coast of Hokkaido. In Pritchard RS ed. Sea Ice Processes and Models: Proceedings of the Arctic Ice Dynamics Joint Experiment International Commission on Snow and Ice Symposium, 6-9 September 1977, Seattle, WA, USA. University of Washington Press, Seattle, 273-282 